\title{
Transcription revisited: A commentary on the 1995 Cold Spring Harbor Laboratory meeting, "Mechanisms of Eukaryotic Transcription"
}

\author{
Steven L. McKnight \\ Tularik Inc., South San Francisco, California 94080 USA; Department of Molccular Genetics, Southwestern Medical Center, \\ Dallas, Texas 75235 USA
}

Several hundred scientists descended upon Cold Spring Harbor Laboratory in the late summer of 1995 to discuss progress in the field of transcriptional regulation at the "Mechanisms of Eukaryotic Transcription" meeting. Similar meetings have been held at 2-year intcrvals, all organized by Winship Herr, Robert Tiian, and Keith Yamamoto. Since the inaugural 1989 meeting, remarkable progress has been made in this field. Herc I attempt to provide an overview of problems and concepts that appear to have been clarified in the field of eukaryotic gene regulation, as well questions that remain eithcr obscure or controversial. This undertaking is meant to be neither comprehensive nor particularly scholarly. I have not attempted to canvass all data presented at the meeting. Likewise, I have not compiled a comprehensive list of references. Readers interested in obtaining detailed background and bibliographical information on the topic of transcriptional regulation are directed to texts authored by Ptashne \{1992\} and edited by Mcknight and Yamamoto (1992).

\section{Impotent enzymes}

The nuclear genes of eukaryotic organisms are transcribed by one of three RNA polymerases. RNA polymerase I (Pol I) is utilized exclusively for the expression of genes encoding the 5.8S, $18 \mathrm{~S}$, and $28 \mathrm{~S}$ ribosomal RNAs (rRNAs). The form II enzyme (Pol II) transcribes all genes encoding mRNAs, as well as those that specify certain small nuclear RNAs (snRNAs). All tRNA genes, as well as the genes for $5 \mathrm{~S}$ rRNA and the remaining snRNAs, are transcribed by RNA polymerase III (Pol III).

Despite the availability of detailed molecular information regarding the three nuclear RNA polymerases, much remains to be learned as to how they operate in a functional sense. As purified entities, each of the enzymes retains the capacity to transcribe DNA if primed from a nicked or single-stranded template. The purified enzymes are, however, incapable of accurate, class-specific promoter recognition. This impotency has stimu- lated highly productive studies on the polypeptide cofactors required to mediate promoter-dependent transcription initiation.

Before reviewing progress reported in this dimension of the field, it is useful to emphasize that such accomplishments have been primed by crisply defined questions and goals. Why are the purified nuclear RNA polymerases incapable of accurate promoter recognition and transcription initiation? Under what conditions or by the abetment of what cofactors can transcriptional fidelity be recapitulated? Similarly clear objectives are now beginning to be articulated for other events in the transcription cycle, such as the clcarance of an engaged polymerase subscquent to its recruitment to a promoter, acquisition of enzymatic processivity, and coupling of the transcription reaction with events leading to the maturation of an RNA product (e.g., RNA splicing, formation of the $3^{\prime}$ terminus of a freshly made transcript, and controlled transport of a newly made RNA from one cellular location to another).

\section{The origins of cofactors}

More than a decade ago, Roeder and colleagues first demonstrated accurate, promoter-dependent transcription initiation by Pol II in a cell-free reaction (Weil et al. 1979). This accomplishment laid the groundwork for biochemical dissection of the reaction. Such early studies were focused on core promoter elements-the DNA sequences that dictate where an RNA polymerase is to land on DNA and in which direction it is to transcribeas well as the protein factors required for their recognition by Pol II.

The most celebrated of the core promoter elements is an adenine/thymine-rich element referred to as the TATA box (for review, see Breathnach and Chambon 1981). A second promoter element, designated the initiator, has been found in the immediate vicinity of the start site of transcription (Smale and Baltimore 1989). Promoters containing a good fit to the canonical se- 
quence $5^{\prime}$-TATAAA- ${ }^{\prime}$, if located $25-30$ bp upstream from a functional initiator element, tend to be transcribed readily in cell-free systems. These canonical promoters, particularly the major late promoter of adenovirus, have formed a cornerstone for biochemical dissection of the transcription initiation reaction.

The earliest mammalian systems that faithfully recapitulated transcription initiation in vitro were prepared either from whole cells (Weil et al. 1979; Luse and Roeder 1980; Manley et al. 1980) or isolated nuclei (Dignam et al. 1983al. Aside from Pol II itself, accurate transcription initiation has been found to rely on a variety of protein components separable by ion-exchange chromatography. Viewed most simply, each of these fractions was assumed to contain an essential cofactor required for the initiation reaction. The nomenclature of essential and important cofactors has evolved from their pattern of elution from ion-exchange columns (Dignam et al. 1983bi.

Two variables have been used to assess the mechanistic contribution of each cofactor - time and space. Definition of a chronological series of events involved in the transcription reaction (promoter occupancy, template melting, synthesis of the first few ribonucleotides of the transcript, promoter escape, and elongation) has made it possible to assess at which step (time) a cofactor is required. The dissection of independent steps undertaken during the transcriptional initiation cycle has been facilitated by the use of gel mobility shift assays that allow the separation and visualization of immature, intermediate, and mature assemblies (Buratowski et al. 1989). With respect to space, it has been useful to detcrminceither by direct DNA-binding assays or functional dependency-where on a promoter a given cofactor acts. By use of these criteria, it has been possible to establish temporal and spatial assignments as to when and where different cofactors are employed in the transcription initiation reaction.

\section{TFIID—clarity and paradox}

By far the most carefully studied cofactor for transcription by Pol II is TFIID. With respect to the issues of time and space ${ }_{i}$ it is known that this factor functions early in the initiation cycle and, in most instances, via a defined promoter recognition element, the TATA box. The polypeptide components of this factor are of two sorts. Central to TFID function is the TATA box-binding protein (TBP). On its own, TBP is capable of avid binding to the TATA box. This single polypeptide is likewise capable of stimulating basal transcription initiation by Pol II. By basal, I refer to in vitro transcription initiation unabetted by gene-specific activator proteins.

TBP was first purified from the budding yeast Saccharomyces cerevisiae (Hahn et al. 1989), and its encoding gene has been cloned from a wide range of organisms (for review, see Hernandez 1993|. Several years ago, the laboratories of Burley and Sigler succeeded in solving the molecular structure of TBP bound to the TATA box (Kim et al. 1993a,b). TBP sits atop DNA much as a saddle strides the back of a horse and creates a sharp bend by cramping the dimensions of the minor groove of DNA on either side of the central nexus of the complex.

Whereas purified TBP is capable of supporting basal transcription initiation in cell-free systems, this likely represents a physiologically irrelevant activity. When isolated from mammalian cell nuclei, TBP is associated with one of several multiprotein complexes. The TBPassociated complex present in the TFIID fraction is essential for transcription of mRNA-coding genes by Pol II. Surprisingly, this same protcin-TBP-is found in entirely different complexes that control transcription of rRNA genes by Pol I, 5S and tRNA genes by Pol III, and snRNA genes by Pol II and Pol III. The polypeptides that associate with TBP in these various complexes have been identified by Tiian for TFIID (Dynlacht et al. 1991), Tiian and Grummt for the SL1 complex essential for Pol I transcription (Comai et al. 1992; Eberhard et al. 1993), Hernandez, Pugh, Weil, and Jackson for the TFIIIB complex that facilitates Pol III transcription (Lobo et al. 1992; Poon and Weil 1993; Taggart et al. 1992; White and Jackson 1992), and Hernandez for the SNAPc complex that facilitates snRNA gene expression by Pol II (Sadowski et al. 1993).

Of these various TBP-containing complexes, the most mature and, paradoxically, controversial story has evolved from studies of TFIID. In the TFIID complex, TBP is associated with eight polypeptides designated TBP-associated factors (TAFs). Numerous plenary and poster presentations at the 1995 CSHL Transcription Meeting dealt with the TAFs. Many of the TAFs have been purified, cloned, and sequenced from organisms including fruit flies, humans, and yeast (for review, see Goodrich and Tjian 1994). Early interest in the TFIID complex arose from the observation that it, unlike purified TBP, is capable of recapitulating activator-dependent transcription (Dynlacht et al. 1991; Tanese et al. 1991; Timmers and Sharp 1991; Zhou et al. 1992; Chiang et al. 1993). Given the inability of TBP to mediate the function of gene-specific transcriptional activator proteins, considerable attention has been focused on the TAFs.

Using recombinant proteins, Tiian and colleagues have reconstituted an intact, functional TAF-TBP (TFIID) complex, as well as partially assembled complexes (Chen et al. 1994). This work has facilitated functional assays for the activities of the various TAFs in the context of activator-dependent transcription initiation. Certain TAFs appear to mold the TFIID complex in a structural sense. Others have been found to interact with the activation domains of gene-specific transcription factors. Because TFIID can support activator-dependent transcription, but TBP cannot, the specific interactions observed between TAF subunits and activation domains provide a sensible means of interpreting the action of gene-specific activator proteins.

Tiian outlined data showing that the activation domain of the hunchback gene product of fruit flies interacts specifically with TAF60, whereas that of the bicoid gene product interacts with TAF110. Optimal in vitro 
transcription of a fruit fly gene known from in vivo studies to be dependent on both of these transcription factors-the hunchback gene itself-was observed only when TBP-TAF complexes containcd both TAF 60 and TAF110. Such observations are consistent with a model in which gene-specific activator proteins function to rccruit the TFIID complex. In the particular case studied by Tjian, all components contain sequence-specific DNA-binding activity. Bicoid contains a homeo domain, Hunchback contains a zinc finger domain, and TFIID contains TBP. As such, the activation reaction can be conceptualized as a cooperative DNA-binding reaction. DNA-bound Bicoid and Hunchback, by virtue of their affinities for specific TAFs, recruit the TFIID complex. Tjian provided evidence of this cooperativity by the use of DNase I footprinting.

The simplicity and potential validity of Tiian's observations were challenged by both Struhl and Green, who reported the results of genetic studies of the TAF proteins in yeast. Although TBP was originally purified from yeast as a single polypeptide, Weil, Green, and others have found that fungi encode proteins similar in primary amino acid sequence to the TAFs of more complex eukaryotic organisms (Reese et al. 1994; Poon et al. 1995!. Whereas Struhl and Green reported that introduction of null mutations into TAF-encoding genes of yeast results in lethality, conditional elimination of their activity did not rapidly affect gene expression. Struhl and Green observed independently that transcription of activator-dependent genes persisted in yeast cclls long after the cells were shifted to conditions expected to inactivate TAF function.

How can these contradictory observations be reconciled? It is possible that Tjian's in vitro studies fail to reveal the bona fide role of TAFs. TAFs may not mediate TFIID recruitment via gene-specific activator proteins but may instead be involved in some other biochemical reaction. Alternatively, the methods used by Struhl and Green may not facilitate the elimination of in vivo TAF function as rapidly as assumed. It is also possible that only a subset of yeast genes are dependent on TAF function and that those studied by Struhl and Green are of a TAF-independent class. Finally, a conceptual gap may separate our understanding of the transcription cycle as enacted in test-tube reactions relative to that occurring in living cells. What, for example, is the fate of the TFIID complex subsequent to its recruitment to a gene and stimulatory action during its first transcription cycle? Does TFIID remain associated with a promoter for multiple rounds of transcription initiation, such that TAFmediated recruitment might be rate limiting only to change the activity state of an otherwise dormant gene?

These questions have been difficult to resolve in testtube assays because of the inefficiency of the transcription initiation reaction. Several studics that have addressed this question gave evidence that TFIID, once promoter-bound, persists through more than one initiation cycle (Van Dyke et al. 1988, 1989; Zawel ct al. 1995). Such questions have proven even more problematic for studies of gene expression in living cells. Moreover, rate- limiting steps observed in vitro may not match those observed in vivo. If so, the observation that activatordependent transcription persists in yeast cells, despite elimination of functional TAFs, might reflect the slow decay of the promoter-bound T'FIID complex. It is also possible that TFIID recruitment, as well as its persistence once recruited, might vary from one gene to the next. Certain genes might hold onto the complex through multiple rounds of transcription initiation by Pol II, whercas others might demand fresh recruitment for every initiation cycle. Given the vigor of the discussion that revolved around this subject, it will undoubtedly attract focused attention in the upcoming years.

\section{TFIIB slots itself in-presage to a deluge of structural studies}

An entire session of the 1995 CSHL Transcription Meeting was devoted to the "Basal Promoter Apparatus". Ebright, in a rousing presentation, outlined the results of an alanine scan study of TBP that was carried out in collaboration with the Reinberg laboratory. By substituting individual solvent-exposed side chains of TBP with alanine and testing the mutated proteins in a variety of assays that monitor the stepwise assembly of the Pol II preinitiation complex, Ebright and colleagues were able to identify regions of TBP required for specific, molecular events involved in the transcription initiation reaction. A localized patch of residues positioned on the upstream side of promoter-bound TBP was identified as the likely interface for interaction with TFIIA, whereas an entirely distinct segment located in the promoter-proximal stirrup of $\mathrm{TBP}$ was found to influence interaction with TFIIB. Berk also reported the results of targeted mutagenesis of TBP. Although making more radical side chain substitutions than Ebright, Berk was also able to map TFIIA interaction to the upstream face of TBP and TFIIB interaction to the downstream stirrup.

Satisfyingly concordant observations were presented by Hahn, who used a variety of techniques to map where TFIIB interacts on DNA and what regions of both TFIIB and TBP are required for co-occupancy of a Pol II promoter. Hahn showed that at least 7 bp of DNA is required both upstream and downstream of the TATA box to support stable, TBP-dependent binding of TFIIB /Lee and Hahn 1995). Such observations, coupled with hydroxyl radical footprinting, led to the prediction that TFIIB binds to DNA on both sides of the TATA box beneath TBP. Using yeast genetics, Buratowski probed TBP-TFIIB interactions, arriving at conclusions well in line with those presented by Ebright, Berk, and Hahn.

Modeling of the TBP-TFIIB complex via biochemical and genetic approaches converged spectacularly in Burley's presentation of the molecular structure of the complex. Using single crystal X-ray diffraction, Burley succeeded in solving a high-resolution structure of a TFIBTBP-TATA element ternary complex (Nikolov et al. 1995). As shown in Figure 1, TFIIB recognizes the preformed TBP-DNA complex, making molecular contacts with the carboxy-terminal stirrup of TBP and the phos- 
Figure 1. X-ray crystallographic structure of the ternary complex of TFIIB recognizing TBP complexed with a TATA element. TFIIB (red and magenta) and TBP (light and dark blue) are depicted as shaded ribbons, and the DNA is shown as a stick figure (green! with the transcription start site labelled with +1 . TFIIB clamps the carboxyterminal stirrup of TBP in the cleft between its two $\alpha$-helical domains and also interacts with the phosphoribose backbone, both upstream and downstream of the TATA box. (Figure kindly provided by D.B. Nikolov and S.K. Burley.)

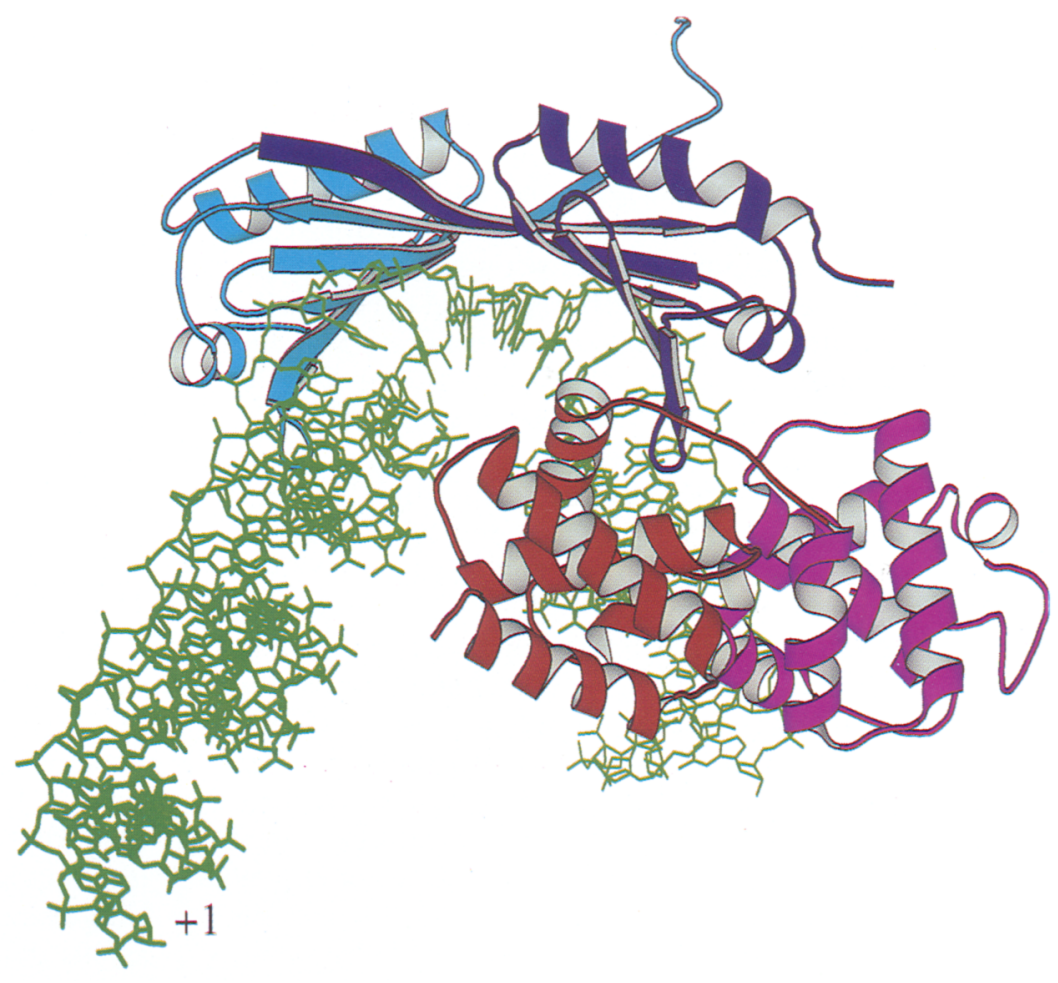

phoribose backbone both upstream and downstream of the TATA element. In addition to stabilizing the TBPDNA complex, TFIIB binding contributes to the polarity of TATA element recognition. It is remarkable that the solution NMR structure of TFIIB displays the same domain structure, with a slightly different arrangement of the two domains (Bagby et al. 1995). These observations suggest that TFIIB undergoes a conformational change on recognizing the TBP-DNA complex. TFIIB forms the downstream surface of the TFIB-TBP-DNA ternary complex, where it could readily act as a bridge between TBP and Pol II to fix the transcription start site.

Although structural studies of the transcriptional initiation complex are only beginning to build the momentum required for significant impact on function and mechanism, there is reason to believe that the seeds for a ripe harvest have been sown. Why, in the face of the historical frustrations experienced by structural biologists interested in multicomponent nucleic acid-protein complexes, is this prediction offered? What should spell the difference for successful structural studies of the transcription initiation complex are its inherent modularity and amenability to stepwise assembly. As biochemists dissect and resolve the events involved in formation of the initiation complex, as well as the protein factors involved, structural biologists will be able to solve the structures of incrementally more complex assemblies. What started with the X-ray structure of TBP in the absence of its DNA template has now evolved to the ternary complex shown in Figure 1. Within a year we are likely to see the heterodimeric TFIIA slotted into this complex. Moreover, although intrinsic technical limita- tions may hinder resolution of a fully assembled complex, subcomponents such as TFIID (9 polypeptides), TFIIE ( 2 polypeptides), TFIIF ( 2 polypeptides), and TFIIH (8 polypeptides) appear to be within reach.

\section{Convergence of Gal11P and the SRBs-activation by recruitment}

Similarly conceived genetic stories relevant to the transcription of Pol II genes were presented by Ptashne and Young. In both cases, partially debilitated strains of budding yeast were employed as a starting point to search for genes involved in the transcription initiation cycle. Ptashne's work began with yeast cells defective in Gal4, the prototype of all eukaryotic transcriptional activator proteins. A decade ago Ptashne and colleagues showed that Gal4 consists of two functional domains, an aminoterminal DNA-binding domain and a carboxy-terminal activating domain (Brent and Ptashne 1986; Keegan et al. 1986, $\mathrm{Ma}$ and Ptashne 1987). In the intervening years, cfforts have been focused on both structural and functional studies of Gal4.

Yeast cells bearing an activation domain-defective form of Gal4 were mutagenized to screen for suppressive mutations. One such mutation mapped to the gene encoding a protein termed Gal11 (Himmelfarb et al. 1990). In an appropriately mutated form, designated Gal11P, this protein suppresses variants of Gal4 that lack its activation domain. How so? Remarkably enough, Ptashne and colleagues have found that the Gall1P protein, unlike native Gall1, has acquired the ability to interact with the DNA-binding domain of Gal4 (Barberis et al. 
1995). Ptashne outlined clear quantitative evidence showing that the binding avidity of Gal11P to its target site within the DNA-binding domain of Gal4 (a coiledcoil dimerization motif), correlates spot-on with its ability to activate gene expression in living cells.

So what in the world is Gall1? Here arrives the connection between the work of Ptashne and Young. Using a conceptually related strategy, Young isolated genetic variants of yeast that restore vitality to cells bearing a truncated form of the largest subunit of Pol II. More specifically, the starting point for Young's work was a defective form of the largest subunit lacking about half of the CTD (carboxy-terminal domain) repeats. Yeast cells expressing a shortened CTD grow slowly yet can be compensated for this defect when mutated at onc of a number of genetic loci (Koleske et al. 1992). These genes encode members of a group of 9 polypeptides, designated SRB proteins, of which Ptashne's Gall1 protein is a member. The SRB proteins form a biochemically defined complex that can be isolated as either a distinct entity or in association with an even larger complex containing Pol II, TFIIB, TFIIF, and TFIIH (Thompson et al. 1993; Koleske and Young 1994; Hengartner et al. 1995).

Indeed, the SRBs-in association with Pol II-appear to comprise the yeast form of a Pol II "holoenzyme". Attendees of the meeting also witnessed the reporting of two mammalian forms of the Pol II holoenzyme. Young presented the purification of a Pol II holoenzyme from calf thymus while Sheldon (Reinberg laboratory) discussed the isolation of a human holoenzyme. Moreover, the purification of a mammalian holoenzyme from rat liver extracts was published recently by the laboratories of Nigg and Schibler (Ossipow et al. 1995).

The combination of Ptashne's Galll and Young's SRB work provides refreshing insight to the problem of transcriptional activation. Gal4, if lacking a functional activation domain, cannot stimulate the expression of its normal battery of target genes. Upon mutation of Gall1 to the Gall1P variant, the defective Gal4 protein acquires the ability to recruit the SRB/Pol II complex. Whereas this acquired function may not reflect the mechanism by which native Gal4 activates gene expression, it shows clearly that SRB/Pol II complex recruitment can constitute a rate-limiting step in the transcription cycle. The beauty of the observation is that it can now be viewed in a clear, mechanistic sense. What we have here is a strong correlation between in vivo and in vitro data condensed down to a single protein-protein interaction. Much like Tiian's interpretation of TFIID recruitment via specific protein-protein interactions between activation domains and TAFs, the Gall1P story points to specific protein-protein interaction as the basis of SRB/Pol Il complex recruitment.

Other than Gall1, what are the polypeptide constituents of the SRB complex and how do mutations in the genes encoding SRB proteins overcome the shortcomings of a truncatcd CTD? Of the mutations that reveal SRB function, one class behaves in a genetically dominant manner. The proteins encoded by this group of genes might function, at least when altered to the SRB pheno- type, in much the same way as Gall1P in genetic parlance, via a gain-of-function route). In their SRB-mutated form they might adopt and expose protein interfaces that facilitate recruitment of the SRB/Pol II complex despite the presence of a truncated Pol II CTD. Alternatively, the dominant SRB mutations might encode proteins that, rclative to their native statc, somehow tighten the SRB/Pol II complex, thereby overcoming partial unraveling that results from the truncated Pol II CTD.

From my vantage, even more insightful information has evolved from SRB mutations that act in a genetically recessive manner. Young reported that two of these recessive SRB mutations map to genes encoding a cyclindependent kinase (CDK) activity. This conclusion was drawn from Young's own work on SRB mutants (Liao et al. 1995!, as well as that of Carlson, who independently discovered the same CDK in studies of glucose-mediated transcriptional repression in yeast (Kuchin et al. 1995). Apparently, the mutated forms of these proteins that restore function to a shortened Pol II CTD /designated SRB10 and SRB11 by Young and SSN3 and SSN8 by Carlson) represent loss-of-function mutations with respect to CDK activity. Why would the loss of a specific CDK activity restore function to CTD-truncated Pol II? Before addressing this question it is necessary to review prior studies on the Pol II CTD.

\section{CTD at the hub of the wheel}

Ingles and Corden discovered the CTD about a decade ago upon cloning and sequencing the gene encoding the largest subunit of Pol II (Allison et al. 1985; Corden et al. 1985). In the intervening years, few protein domains studied in the transcription field have received more attention than the CTD. Through the work of Corden, Dahmus, Greenleaf, Ingles, and others, several important questions have been resolved. First, the CTD is essential for the in vivo function of Pol II (Nonet et al. 1987; Allison et al. 1988; Bartolomei et al. 1988; Zehring et al. 1988). Second, it revolves through a covalent modification cycle wherein the CTD is heavily phosphorylated during transcriptional elongation, yet hypophosphorylated prior to the onset of transcription initiation (Laybourn and Dahmus 1989, 1990). Third, it is a ripe substrate for a variety of CDKs /Cisek et al. 1989; Lee and Greenleaf 1989).

Several new observations relevant to the CTD were reported at the 1995 CSHL Transcription Meeting. Dahmus devised a means of decorating the CTD with a radioactive, photo-cross-linking reagent that allowed detection of proteins closely associated with the CTD. Using an innovative label transfer assay, Dahmus provided evidence of close interaction between the CTD and at least two of the general transcription factors (TFIIE and TFIIF), as well as tentative indications that it might also contact other cofactors required for transcription initiation. Kornberg, Egly, Young, and Reinberg have independently shown that at lcast one of these cofactors, TFIIH, is endowed with its own CDK activity 'Feaver et al. 
1994; Roy et al. 1995; Serizawa et al. 1995; Shiekhattar et al. 1995).

Here the field appears to have taken a great leap forward. With the fog clearing, I take the liberty of summarizing the image I retrieved from the 1995 CSHL Transcription Meeting. To do so, I start by listing the observations most relevant to the image.

- The Gal11P mutation facilitates direct recruitment of the SRB/Pol II complex into the transcription initiation cycle.

- Members of the CDK family are highly suitable for CTD phosphorylation.

- The SRB complex contains a dedicated CDK.

- The SRB complex functions more effectively on a shortened CTD when its CDK is nonfunctional.

- The CTD interacts intimately with general transcription factors.

- One of the general transcription factors, TFIIH, contains a dedicated CDK.

- TFIIH acts at a late stage of the transcription initiation cycle.

The speculation most central to my image of the transcription initiation reaction identifies the CTD of Pol II as a dynamic integrator governing a series of temporal steps executed during the transcription cycle. As a starting point, Pol II, in its CTD desphosphate form, is associated with the SRB complex. This SRB/Pol II complex may include other general transcription factors, yet the relevant connection I wish to emphasize is the CDK activity of the SRB complex and the CTD desphosphate form of Pol II. Entry of Pol II into this complex is hypothesized to be dependent on the intact, hypophosphorylated $C T D$ and mediated via its interactions with either SRB polypeptides or otherwise appended cofactors.

The SRB/Pol II complex first becomes engaged in an initiation cycle following its recruitment to a class II gene (Fig. 2, top). Experimental evidence available to date has not established a direct, promoter-independent connection between the SRB/Pol II complex and the TBP/ TAF (TFIID) complex. As such, the convergence of these two entities is presumed to be nucleated at the promoter. The independent recruitment of the two complexes starts the process of transcription initiation with two rate-limiting steps that have been implicated by biochemical (TFIID recruitment) and genetic (SRB/Pol II complex recruitment) studies. Either or both of these steps may be facilitated by the activation domains of gene-spccific transcription factors.

Subsequent to this convergence, I predict the occurrence of a transition step involving partial phosphorylation of the Pol II CTD and release of the SRB complex (Fig. 2, middle). This step is invoked by virtue of the phenotypes of SRB mutations that eliminate the enzymatic function of the SRB-associated CDK. Because these mutants suppress CTD-truncated forms of Pol II, it can be interpreted that the kinase-defective SRB is more apt to hold onto the Pol II enzyme bearing a truncated CTD. More specifically, I predict that the CDK activity of the native SRB complex is imbalanced when paired with a shortened Pol II CTD. This hypothetical balance is predicted to be gauged by the phosphorylation level of the CTD and manifested by CTD adherence to the SRB complex in its hypophosphorylated form and release upon partial phosphorylation. When Pol II is compromised by removal of a significant number of the CTD heptapeptide repeats, the hypothetical CDK/CTD phosphorylation balance is predicted to be shifted sufficiently

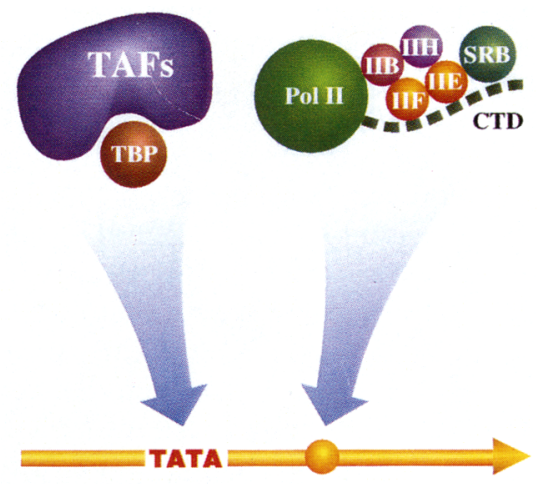

Recruitment via Gene-Specific Activators
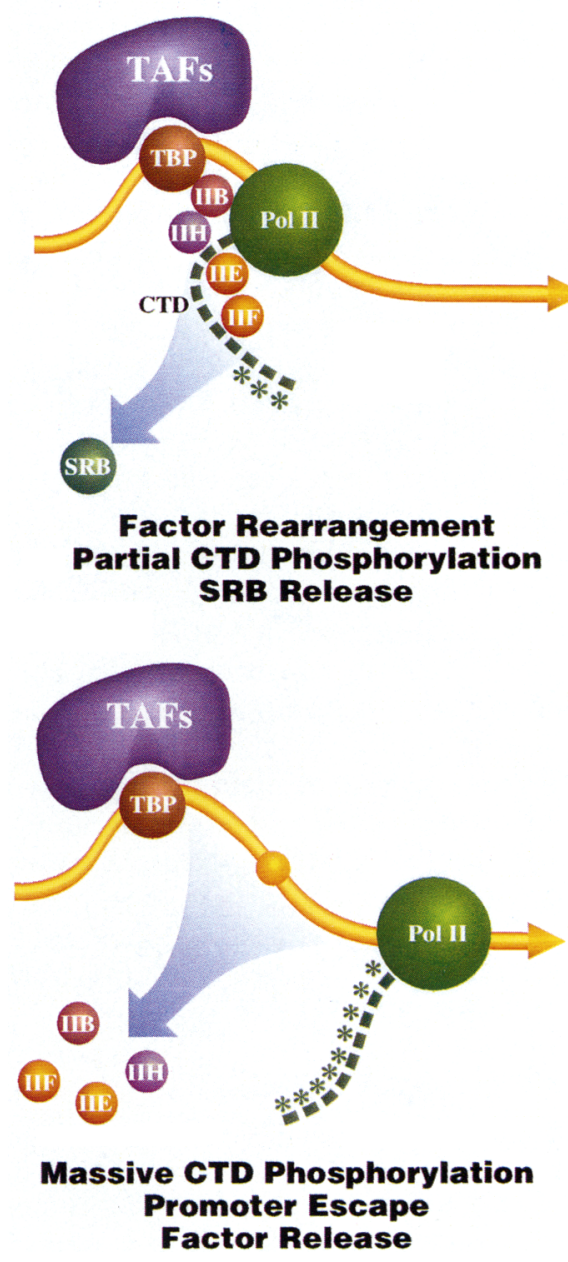

Figure 2. (See facing page for legend.) 
toward the phosphorylated side of the ledger so as to prematurely release Pol II from the SRB complex. If, as intuited by Ptashne, Pol II recruitment can be mediated via interactions between SRB polypeptides and the activation domains of gene-specific transcription factors, the attenuated avidity of CTD-truncated Pol II for the SRB complex would be expected to proportionally compromise Pol II recruitment.

The scenario outlined in the preceding paragraph is consistent with biochemical experiments conducted by Kornberg and colleagues. They have described a mediator activity required to support activator-dependent transcription in test-tube reactions derived from yeast (Kelleher et al. 1990; Flanagan et al. 1991|. This activity, which probably corresponds to the SRB complex, can be dissociated from Pol II by use of monoclonal antibodies to the CTD. When the isolated mediator/SRB complex is mixed with Pol II and TFIID, activator-dependent transcription initiation is restored (Kim et al. 1994). Of key importance to the image of the transcription cycle developed herein is the fact that CTD-specific antibodies dissociate Pol II from the mediator/SRB complex.

As mentioned previously, upon converging with TFIID at a promoter, the SRB/Pol II complex is predicted to isomerize in a manner resulting in SRB release (Fig. 2, middlel. It is further assumed that the biochemical basis of this release corresponds to an enhanced level of CTD phosphorylation. The input signals that lead to CTD phosphorylation are unknown yet might entail the altered arrangements of general transcription factors. Young has observed, for example, that the SRB/Pol II complex contains TFIIB (Koleske and Young 1994). Subsequent to recruitment, TFIIB locks into place beneath DNA-bound TBP as shown in Figure 1. This or other factor rearrangement events may be sensed by the CDK of either the SRB complex or TFIIH, thereby resulting in enhanced CTD phosphorylation. Following this line of thinking it is intriguing that the three-dimensional structure of TFIIB is related to that of cyclins, which are known to serve as dedicated activators of CDKs. Because comparative examination of the structure of TFIIB off and on DNA gives evidence of a substrate-mediated conformational change, it is perhaps possible that this might potentiate the ability of TFIIB to act as a cyclin-like cofactor for one of the CDKs involved in the transcription initiation cycle.

Changes in the activities of either of these CDKs might also be stimulated by yet-to-be-discovered signaling activities associated with the TFIID complex. When placed in proximity to a freshly recruited SRB/Pol II complex, the TAFs might transmit signals that isomerize the complex. Finally, heightened CTD phosphoryla- tion-resulting in SRB release-might result from the newfound proximity of the Pol II complex to gene-specific transcriptional activator proteins.

What is the fate of the recruited Pol II complex following SRB release? I have hypothesized that this event is enacted following partial phosphorylation of the CTD and speculate further the existence of a subsequent ratelimiting step that is dependent on massive CTD phosphorylation (Fig. 2, bottom). Evidence for this second, CTD-sensed step derives largely from the work of Lis and colleagues, which will be reviewed subsequently.

Before addressing this evidence, however, it is useful to review the observations that justify focused attention on CTD phosphorylation in the context of the control of transcription initiation. First, we know from the work of Dahmus and others that CTD phosphorylation fluctuates dramatically as a function of the transcription cycle. Second, Egly, Komberg, Carlson, Young, and Reinberg have shown that transcription by Pol II likely entails the use of at least two CDKs. Third, Corden and Greenleaf have found that the Pol II CTD is a ripe substrate for members of the CDK family of serine/threonine kinases. Given that CDKs represent the master sensing apparatus utilized to control cell-cycle progression (for review, see Nasmyth 1993; and Morgan 1995), the CDK activities associated with the SRB complex and TFIIH obviously qualify as potential master regulators of the Pol II transcription cycle. Here, I believe, the field has uncovered a fresh mechanistic concept that may explain how events in the initiation reaction are ordered and regulated. Instead of limiting our conception of the activation process to protein-protein interactions and complex recruitment events, we can now postulate the involvement of an enzymatic cascade that utilizes CDKs as information sensors and the Pol II CTD as a molecular integrator. That is, the transcription cycle, may operate in a manner not unlike the cell cycle and be governed by the same type of molecular apparatus (CDKs).

\section{Pol II on heat shock genes-stalled for a decade}

The clearest evidence indicating that Pol II recruitment is not the sole, rate-limiting step in the transcription cycle of every gene comes from the work of Lis and colleagues. By use of a variety of techniques, including photo-cross-linking and potassium permanganate footprinting, Lis has discovered that latent heat shock genes of metazoans contain an engaged RNA polymerase molecule (Rougvie and Lis 1988; Giardina et al. 1992). At ambient temperature, Pol II is stalled $20-30$ bp internal to the gene, having progressed sufficiently late into the initiation reaction to produce a transcript of correspond-

Figure 2. Hypothetical rate-limiting steps encountered during the process of transcription initiation by RNA polymerase II. (Top) Initial recruitment events bringing the TBP/TAF complex (TFIID) and SRB/Pol II complex to a promoter. Each step may be enhanced by intrinsic complex-DNA affinity (i.e., TBP affinity for the TATA box) or by attractive protein-protein interactions formed via gene-specific activator proteins (not shown). (Middle) Template-mediated factor rearrangements (e.g., newfound interaction between TBP and TFIIB), partial CTD phosphorylation, SRB release, and formation of a stably engaged preinitiation complex. (Bottom) Dissolution of the preinitiation complex, massive CTD phosphorylation, transition of engaged Pol II into an elongation-competent enzyme, and release of transcriptional cofactors. 
ing size. Upon heat shock, a gene-specific transcription factor designated heat shock factor (HSF) is converted rapidly from the monomeric to trimeric state and binds to heat shock elements (HSEs) located upstream of the stalled RNA polymerase (for review, see Lis and $\mathrm{Wu}$ 1993). As a result, heat shock genes are transcribed by elongation-competent, hyperphosphorylated Pol II.

Interpreted most simply, transcription of heat shock genes does not appear to be rate limited by Pol II recruitment. Although formally unproven, it is assumed that following induction by HSF, the stalled RNA polymerase is modified so as to facilitate promoter escape and productive transcriptional elongation. The only firmly substantiated change in Pol II during this reaction is CTD phosphorylation, which Lis has observed using molecular biological methods (O'Brien et al. 1994) and Greenleaf has determined by immunohistochemical staining of polytene chromosomes of fruit fly salivary glands (Weeks et al. 1993). Is CTD phosphorylation the actual event that facilitates promoter escape? If so, how is this reaction influenced by HSF? Finally, how-in a mechanistic sense-would CTD phosphorylation release a stalled Pol II enzyme from the heat shock promotcr?

The former two questions were addressed by Bentley, who has studied how different activator proteins facilitate the transcription reaction. Using nuclear runoff assays, Bentley has provided evidence for three categories of transcriptional activators: ones that stimulate only initiation, ones that stimulate only clongation, and ones that stimulate both processes (Yankulov et al. 1994). Interestingly, the ability of gene-specific activators to stimulate transcriptional clongation appears to correlate with their ability to bind TFIIH-one of the two CDKcontaining complexes involved in the Pol II transcription cycle. Bentley reported that pharmacological inhibitors of CDK activity selectively inhibit transcriptional elongation-relative to initiation. Moreover, antibodies to TFIIH, when injected into frog oocytes, were found to inhibit elongation by activated transcription complexes. Finally, Bentley reported that yeast strains bearing a temperature-sensitive form of the TFIIH CDK (kin28ts) were selectively defective in transcriptional elongation.

Coupling the observations reported by Lis and Bentley, it has become clear that gene-specific activator proteins can function at steps subsequent to the recruitment of Pol II. Because CTD phosphorylation appears to accompany the dislodgment of a stalled RNA polymerase, the CDK of TFIIH emerges as an appealing candidate for sensing the function of activator proteins that operate late in the transcription cycle. As to mechanism, the simplest interpretation follows that suggested earlier for SRB-CTD interaction. The hypophosphorylated, or partially phosphorylated CTD might adhere to promoterbound transcription factors, thereby impeding Pol II from productive elongation. Upon substantive phosphorylation, perhaps via the CDK activity of TFIIH, the CTD is predicted to free itself from the promoter and allow Pol II to embark into the elongation phase of the transcription cycle (Fig. 2, bottom). I again emphasize that CDKs, when viewcd in light of their regulatory ca- pacities in the context of other ordered, cellular cascades, represent appealing candidates to sense and integrate the action of gene-specific transcriptional regulatory proteins.

Several presentations provided evidence of ample opportunity for regulation subsequent to promoter escape by Pol II. Aso (Conaway laboratory), reported beautiful data on the elongins, a highly conserved class of Pol II transcription factors that facilitate elongation of RNA synthesis by Pol II. Corden provided evidence for interaction between heterogenous nuclear ribonucleoprotein (hnRNPs) and the CTD, raising the possibility that Pol II might nucleate the formation of the RNA processing apparatus on freshly made transcripts. Finally, Greenleaf rcported evidence favoring the involvement of a CDK activity entirely distinct from that associated with the SRB or TFIIH complexes.

\section{Gene-specific activators-new shapes and mechanisms}

The 1995 CSHL Transcription Meeting could have easily included a dozen additional sessions on gene-specific transcription factors. One might have imagined that preceding discoveries over the past decade-accounting for the description of roughly 500 different factors at last count-might have saturatcd all potential mechanisms for genetic control. No such luck-the pace of discovery seems unabated.

Here are the sorts of questions being addressed relative to the action of gene-specific transcription factors. First, what is the biological circuit coordinated by a factor? Second, how does the factor selectively interact with the appropriate battery of genes? Third, what mechanisms are used to regulate the activity of the factor? Spectacular progress relating to each of these issues was reported in numerous sessions of the meeting by virtuc of a variety of experimental techniques. What follows is an abbreviated listing of accomplishments I found to be particularly noteworthy.

One of the most mature stories concerning regulatory circuitry has been built from studies of cell-type specification in yeast. Herskowitz, Johnson, Nasmyth, Sprague, and othcrs have identified the key regulatory components and provided a compelling mechanistic description of how gene expression is appropriately controlled as a function of mating type (for review, see Johnson 1995|. With respect to the transcription factors that regulate the sexual phenotype of yeast, three are encoded by the mating type loci $\mid \alpha 1, \alpha 2$, and al $\}$ and one is ubiquitously expressed (MCMl). With the exception of $\alpha 1$, these proteins function as genetic repressors, serving to recruit a generalized repression complex (TUP1/SSN6) to the appropriate battery of genes. Asexual, diploid $(\mathbf{a} / \alpha)$ cells express both $\alpha 2$ and a1, which have been known for some time to bind cooperatively to genes that must be inactivated in the diploid state. Cells of the $\alpha$ mating type express $\alpha 1$, which combines with MCM1 to activate $\alpha$-specific genes and $\alpha 2$, which combines with MCM1 to repress a-specific genes. Finally, cells that express only al, which is incapable of functioning on its 
own, assume the a mating type by default. The codependent functions of $\alpha 2 / \mathbf{a} 1$, $\alpha 2 / \mathrm{MCM}$, and $\alpha 1 / \mathrm{MCM} 1$ have emerged as three of the fields clearest examples of combinatorial genetic regulation.

Wolberger used single crystal X-ray diffraction methods to resolve the molecular structure of the $\alpha 2 / \mathrm{al} \mathrm{com-}$ plex on DNA (Li et al. 1995). Despite bearing a homeo domain DNA-binding motif, al is incapable of avid interaction with DNA. However, when abetted by $\alpha 2$, a stable, ternary complex is formed. In the crystal structure, $\mathbf{a} 1$ and $\alpha 2$ bind head-to-tail on one face of DNA /Fig. 3). Heteromeric contact is made between the carboxy-

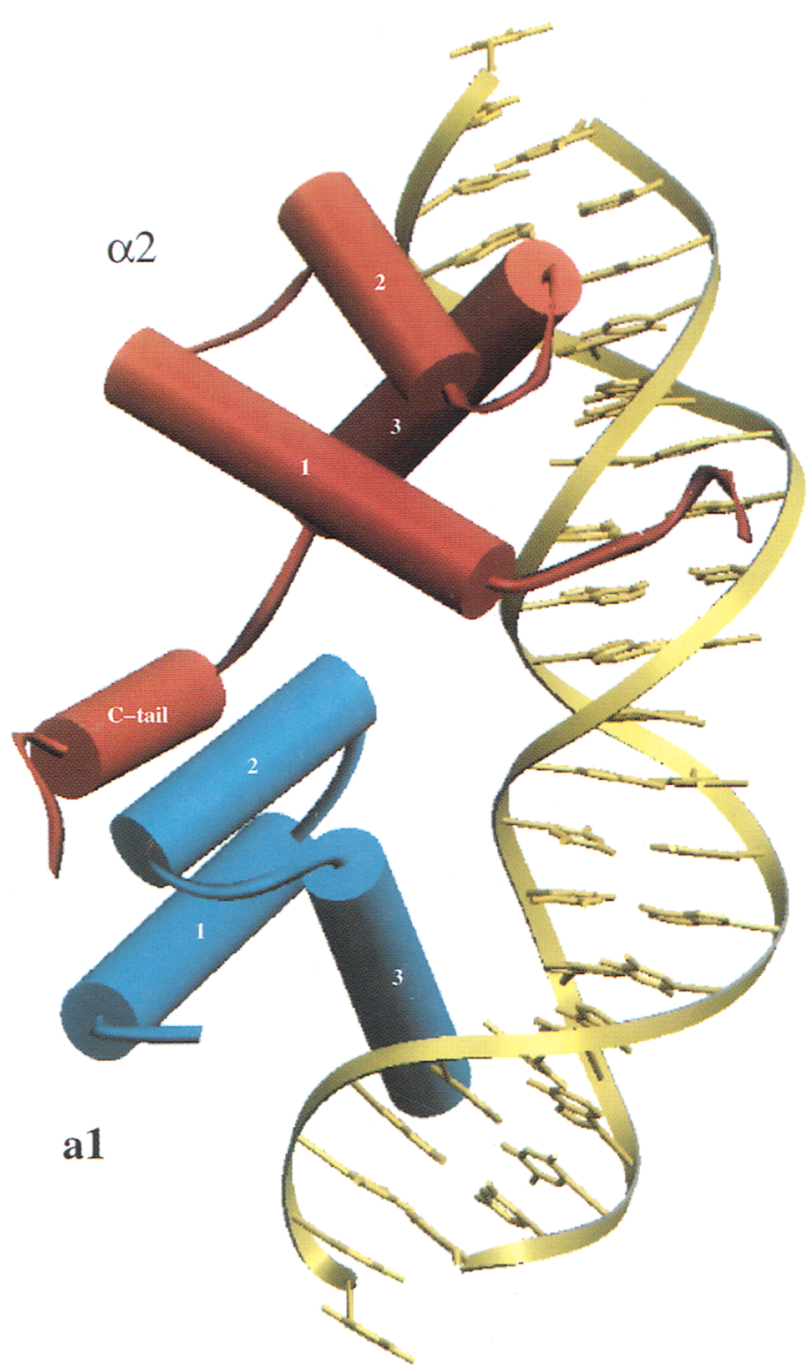

Figure 3. X-ray crystallographic structure of the ternary complex formed by a 1, $\alpha 2$, and DNA. The $\alpha 2$ protein is shown in red, and the al homeo domain in blue. a2-Helices are numbered according to conventions as homeo domain helices 1,2 , and 3 . The $\alpha 2$ protein contains an additional $\alpha$-helix (C-tail) located on the carboxy-terminal side of its homeo domain. This C-tail $\alpha$-helix packs between $\alpha$-helices 1 and 2 of the al homeo domain, forming the heteromeric interface. Binding of the a $1 / \alpha 2$ heterodimer to DNA induces a $60^{\circ} \mathrm{C}$ bend. (Figure kindly provided by $\mathrm{T}$. Li and $\mathrm{C}$. Wolberger.) terminal tail of $\alpha 2$ and the homeo domain of al. The relevant molecular interface contributed by $\alpha 2$ is an amphipathic $\alpha$-helix that packs into the back side of the helix-turn-helix domain of al, thereby fostering its ability to make significant and specific contact with DNA. To my knowledge, Wolberger's presentation offered the field its first molecular view of combinatorial regulation.

Tangentially related to this story was Richmond's description of the crystal structure of the DNA-binding domain of serum response factor (SRF). This domain of SRF is highly related in primary amino acid sequence to the DNA-binding domain of MCM1, the alternative heteromeric partner of the yeast $\alpha 2$ protein. Whereas the field excitedly awaits the resolution of the $\alpha 2 / \mathrm{MCMl}$ heteromeric complex, Richmond's SRF structure was itself remarkable. In it we saw a simple architectural scaffold formed by antiparallel coiled-coil $\alpha$-helices, from which project $\beta$-hairpin loops that interact specifically with the minor groove of DNA (Pelligrini et al. 1995|. Quite obviously, the structure of the SRF DNAbinding domain was not effectivcly predicted by de novo modeling!

One can estimate that roughly one-third of the known protein structural motifs that facilitate sequence-specific DNA binding have now been solved by either NMR spcctroscopy or X-ray crystallography (helix-turn-helix, homeo domain, zinc finger, basic leucine zipper (bZIP), basic helix-loop-helix (bHLH), high mobility group (HMG) domain, winged helix, Rel domain, MADS box domain, TBP). I see no conceptual or technical impediment to the resolution of structures for the remaining classes of DNA-binding protcins, which should tally up to as few as 20-30 principal motifs. Moreover, there is an encouraging reason to believe that structural approaches will be richly rewarding for the study of cooperative interactions between different classes of transcription factors. In most instances studied to date, binding cooperativity by heterotypic proteins can be achieved by the minimal DNA-binding domains of the involved factors.

Several stories relevant to the control of transcription factor activity were noteworthy. Goldstein summarized the regulatory circuit responsible for controlling the biosynthesis and uptake of cholesterol in mammalian cells. When cells are starved for cholesterol, genes encoding rate-limiting biosynthetic enzymes, such as HMG-CoA synthase, are activated. Likewise, the low density lipoprotein receptor gene is also activated, such that exogeneous supplies of cholesterol can be imported into the cell. Gene activation in response to cholesterol starvation is mediated via the sterol response element (SRE) [Smith et al. 1989), which binds a transcription factor designated sterol response element binding protein (SREBP) (Briggs et al. 1993; Hua et al. 1993; Wang et al. 1993; Yokoyama et al. 1993). Under normal conditions, SREBP is tethered to the nuclear envelope or endoplasmic reticulum as a latent transcription factor. Remarkably, in response to cholesterol starvation, SREBP is proteolyzed so as to release the mature form of the transcription factor (Wang et al. 1994). Thus, proteolytic maturation can be addcd to the list of regulatory mech- 
anisms utilized to control the activity of eukaryotic transcription factors.

Graves addressed a related question concerning intramolecular regulation of transcription factor activity. Through studies of the Ets-1 transcription factor, Graves demonstrated that a minimally trimmed DNA-binding domain, the 85-amino-acid ETS domain, binds DNA more avidly than the intact protein. By use of a combination of proteolytic, spectroscopic, and molecular biological methods, inhibitory segments were identified on the immediate amino- and carboxy-terminal sides of the ETS domain. The ability of these domains to mask Ets-1 DNA-binding activity was observed to be codependent, leading Graves to speculate that the two inhibitory domains in some way coalesce to suppress DNA-binding activity. This concept is modeled graphically on the structure of the Ets-1 DNA-binding domain shown in Figure 4 (Donaldson et al. 1996).

Upon DNA binding, the amino-terminal inhibitory domain of Ets-l becomes highly sensitive to proteolytic digestion, offering a means of considering how transcription factors might adopt new activities subsequent to their adherence to target genes (Petersen et al. 1995). I judge this latter observation to be insightful for two reasons. As mentioned earlier, subtle rearrangements of factor assembly may be sensed as a signal during the transcription cycle. Second, DNA-mediated changes in transcription factor conformation might help restrict multiprotein complex formation to assemblies templated by a gene. Treisman, for example, has discovered

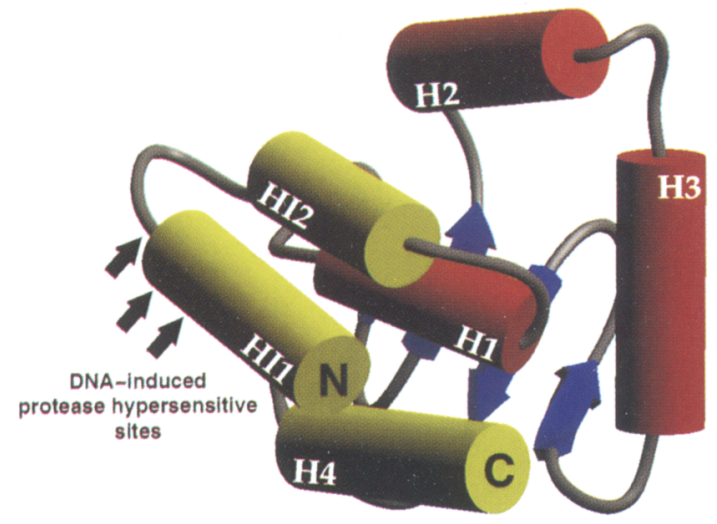

Figure 4. NMR structure of the Ets-1 DNA-binding domain, a winged helix-turn-helix protein composed of a threc-helix bundle (red) and a four-stranded, antiparallel $\beta$-sheet (blue). Helices $\mathrm{H} 2$ and $\mathrm{H} 3$ form the helix-turn-helix motif. An inhibitory module composed of helices $\mathrm{HI}-1, \mathrm{HI}-2$, and $\mathrm{H} 4$ (green) negatively regulates Ets-1 DNA binding via linkage to $\mathrm{H} 1$ of the DNAbinding domain. HI-1 and HI-2 are modeled from secondary structure data and perturbations of the chemical shifts of $\mathrm{Hl}$ and H4. Unfolding of HI-1, as detected by enhanced protease sensitivity, accompanies DNA binding. This altered conformation is predicted to disrupt the packing of the inhibitory module and to provide a potential interface for cooperative interaction with heteromeric partner proteins. (Figure kindly provided by $\mathrm{B}$. Graves and L. McIntosh.) a segment located immediately downstream from the ETS domain of Elk-1 (another member of the Ets family of DNA-binding proteins) that mediates cooperative interaction with SRF (for review, see Triesman 1994). DNA binding by Elk-1 might liberate its SRF contact surface, such that its interaction with SRF is template limited.

The stories reported by Graves and Treisman point to allosteric changes that may alter the structure of a transcription factor as a result of its interaction with DNA. Similar interpretations were forwarded by Yamamoto, who has found that the glucocorticoid receptor (GR) can either activate or repress transcription depending on how it is tethered to a target gene. When bound to a simple, glucocorticoid response element (GRE), GR activates gene expression. In contrast, when tethered to DNA via certain composite GREs, GR can selectively repress gene expression (Sakai et al. 1988). Yamamoto reported the identification of a single lysine residue within the GR DNA-binding domain (K461) that, when mutated to alanine [K461A\}, selectively eliminates the ability of GR to facilitate genetic repression. Instead of repressing gene expression when bound to composite GREs, GR carrying the K461A mutation activates transcription. Yamamoto hypothesized that the nature of the DNA sequence to which GR binds can dictate its function as either an activator or repressor and that the $\mathrm{K} 461 \mathrm{~A}$ variant might be incapable of properly interpreting this DNA-mediated signal.

The alternative function of nuclear hormone receptors as either genetic activators or repressors is probably mediated by polypeptide cofactors. Onate and O'Malley reported the results of a yeast two-hybrid screen that utilized the hormone binding domain of the progesterone receptor (PR) as bait. Such efforts led to the identification of a protein designated SRCl that was shown to bind PR in a ligand-dependent manner and function as a liganddependent coactivator in transiently transfected cells. In a related series of experiments, Evans described the cloning of a putative corepressor for the thyroid hormone (TR) and retinoic acid (RA) receptors (Chen and Evans 1995). Unlike GR and PR, TR and RA bind DNA in the absence of ligand and bring about transcriptional repression, which is reversed upon ligand binding. Evans reported the discovery of a polypeptide designated SMRT, which binds TR and RA only in the absence of ligand and functions in transfected cells as a corepressor-precisely reciprocal to the story reported by Onate for PR. Evans' SMRT protein is functionally and structurally related to $\mathrm{N}-\mathrm{CoR}$, a corepressor of nuclear hormone receptors discovered recently by Rosenfeld and colleagues (Horlein et al. 1995).

\section{Chromatin-remodeling old fashions}

The question of how DNA is wrapped into nucleoprotcin-chromatin-has been of interest and concern to transcriptionologists long before the field "went molecular". Indeed, one of the first international meetings that focused on eukaryotic gene regulation was the 1977 Cold 
Spring Harbor Symposium on Chromatin. Although it is obvious that the nature of the nucleoprotein template must influence how genes are expressed in nucleated cells, it has been difficult to assess whether chromatin structure regulates gene expression or whether gene expression regulates chromatin structure.

Since the discovery of the nucleosome, the most substantive progress in the chromatin field-at least as it relates to gene expression -.has come from genetic studies in yeast and fruit flies. Recessive mutations have been discovered that derepress the transcription of broad chromosomal regions. In flies, for example, mutants have been described that derepress the transcription of homeotic loci that can include many separate genes and extend over hundreds of kilobases of DNA. These include Polycomb and a functionally related set of genes termed Extra sex combs, Enhancer of zeste, Sex comb on midleg, Sex comb extra, Polycomb like and Anterior sex combs (for review, see Bienz and Muller 1995). Cloning and molecular characterization of the products of these genes has led to the discovery of chromatin-associated proteins that act to repress transcription over relatively broad chromosomal regions. Similar studies have led to the discovery of fungal proteins that also serve to repress large chromosomal domains, including regions encompassing the silent mating type loci and telomeres (for review, see Dillin and Rine 1995). I will return to the relevance of this category of regulatory proteins in the context of a newly discovered protein complex that may countervene their role in genetic repression.

Evidence of more selective, gene-specific changes in chromatin structure has emerged from DNase I mapping studies focused on the arrangement of nucleosomes around specific genes as a function of their state of transcriptional activity. The gold standard for such studies has been the PHO5 promoter of yeast. Upon phosphorous starvation, yeast cells activate a signaling pathway that culminates in the binding of a gene-specific activator, Pho4, to the PHO5 promoter. O'Shea reported progress on the signaling pathway that culminates in formation of active Pho4 protein. Evidence was presented showing that the activated Pho4 protein translocates from cytoplasm to nucleus, where it binds to target sites, including the promoter of the PHO5 gene. This process results in the rearrangement of four nucleosomes normally located at invariant positions along the PHO5 promoter and subsequent activation of PHO5 gene expression (Svaren et al. 1994). McAndrew and Horz reported that Pho4-mediated nucleosome repositioning is dependent on a competent Pho4 transcriptional activation domain. Moreover, the effects of different Pho4 mutations on chromatin remodeling and transcriptional activation were observed to be highly concordant, raising the possibility that the primary role of the activation domain might be dedicated to nucleosome reorganization.

Horz and Ptashne joined forces to ask whether nucleosome remodeling is either a consequence or determinant of gene activation. In a clever series of experiments, a fusion protein was made linking the DNA-binding domain of Pho4 to Galll. The Pho4-Gall1 hybrid protein behaved as a potent activator of $\mathrm{PHO}$ gene expression and likewise prompted effective nucleosome repositioning. This observation was interpreted to reflect the recruitment of the SRB/Pol II complex directly to the PHO5 promoter (recall that Gall1 is a normal constituent of the SRB/Pol II complex). Because Galll is not a conventional activator protein, Horz and Ptashne interpreted these observations to indicate that chromatin remodeling results from transcriptional activation, rather than prompting it. Even more compelling were experiments involving a chimeric protein that linked the DNA-binding domain of Pho4 to the dimerization domain of Gal4 (the region of Gal4 that is known to interact directly and specifically with Gall1P). In this case, transcriptional activation of the PHO5 gene and nucleosome remodeling were only observed in cells bearing the Gall1P mutation. Because remodeling was only observed under conditions that permitted recruitment of the SRB/Pol II complex, Horz and Ptashne concluded that nucleosome disruption occurs as a consequence of transcriptional activation and not as its prerequisite.

Although the aforementioned experiments indicate that chromatin remodeling occurs as a consequence of gene activation, a series of recent genetic experiments give reason to believe that nuclcosome disruption represents an important gauntlet that must be negotiated during the activation process. A class of recessive mutations has been discovered in yeast that globally impede the process of de novo gene activation. These genes encode products variously termed switch (SWI) or sucrose nonfermentable (SNF) proteins (for review, see Winston and Carlson 1992). Genetic studies pertinent to SWI/SNF function have revealed the interdependent roles of five different gene products, including SWI1, SWI2/SNF2, SWI3, SNF5, and SNF6 (for review, see LaMarco 1994). Moreover, all five of these proteins coclute in a large complex when yeast extracts are fractionated by molecular sieve chromatography |Cairns et al. 1994; Peterson ct al. 1994; Treich et al. 1995). As to biochemical function, the only clearly established activity of the SWI/ SNF complex is its ability to hydrolyze ATP in a DNAdependent manner (Laurent et al. 1993).

Evidence that the SWI/SNF protein complex might be involved in chromatin remodeling has been inferred from genetic studies of brahma, the putative fruit fly homolog of SWI2/SNF2 (Tamkun et al, 1992). Recessive brahma mutations can suppress loss-of-function mutations in the Polycomb gene. Because the products of the Polycomb group of genes are believed to facilitate chromatin-mediated transcriptional repression, it was reasonable to anticipate that the normal activity of the Brahma gene product-as well, perhaps, as that of the SWI/SNF complex-might serve to loosen chromatin so as to facilitate the access of transcriptional regulatory proteins.

Many interesting talks relating to chromatin were presented at the CSHL Transcription Meeting, including plenary presentations by Kingston, Kadonaga, and Peterson. One of the highlight presentations was delivered by Wu. For the past several years Wu has studied the ability 
of a gene-specific transcription factor, designated GAGA, to invade and bind nucleosome-covered DNA. This GAGA-binding reaction entails nucleosome rearrangement, is ATP dependent, and is catalyzed by a soluble extract derived from fruit fly embryos (Tsukiyama et al. 1994). Using a nucleosome remodeling reaction as an assay for biochemical fractionation, Wu purified an activity termed nucleosome remodeling factor (NURF). The most purified NURF preparations fractionate as a very large complex containing four polypeptides. Partial amino acid sequence analysis of one of the subunits allowed cloning of its encoding gene, which, upon sequencing, revealed substantive similarity to the yeast SWI2/SNF2 and fruit fly Brahma proteins! Thus, genetic and biochemical approaches appear to have converged on a multiprotein complex that mediates chromatin remodeling during the process of gene activation. Whereas many questions remain, it now appears that concrete issues can be addressed concerning the relationship between gene activation and chromatin structure. For example, is Wu's NURF complex selectively recruited during the process of gene activation? If NURF activity is required for gene-specific activators to attach themselves firmly to a remodeled promoter, one might assume that its function must precede-or at least occur concomitant to- that of the activator protein. Is NURF activity operating throughout the genome, dynamically destabilizing chromatin so as to facilitate the function of activators when and where they are destined to land? Alternatively, is it possible that the NURF complex is itself associated with other components of the transcriptional machinery (the SRB/Pol II complex or one of the TAF complexes) and is selectively recruited during the activation process? Although it might seem that the current work on chromatin remodeling may raise morc questions than it has answered, the field is now armed with a sharp set of teeth.

\section{Perspectives-no time to rest}

Each of the transcription regulation meetings I have attended over the past several decades has left me with information overload. Although I have tried to summarize and conceptualize where the ficld is and where it might be heading, I caution that such visions are invariably wrong-waiting only to be spoiled by concretc discoveries. I offer a parting thought that may help emphasize how expansive a space we have the fortune to be working within. Despite the utility of reductionism, it takes little insight to realize that the processes and reactions being studied in the field of gene regulation are far more concerted than presently envisioned. For example, if one predicts that the transcription cycle entails the negotiation of a stepwise series of events, it by no means follows that molecular assemblies are constantly being built, radically disassembled, and rebuilt. The various cofactors required for Pol II to transit its way through the initiation cycle are probably assembled as a cohesive complex. Rather than invoking dramatic asscmbly-reassembly reactions as illustrated in Figure 3, a series of stepwise modifications working on a intact complex more likely control its pathway through the transcription cyclc. Indeed, the transcription cycle may flow largely intact-from its earliest initiation steps to the formation of a mature RNA that can entail the transcription of $>100,000$ bp of DNA. Regulation, no doubt, will seize any available step along this pathway-including ones that may not easily be teased apart in test-tube reactions. I close with the safest of all possible predictions: Despite remarkable progress and plenty of forward momentum, the transcription field is in for many more surprises.

\section{Acknowledgments}

Many people helped in the composition and editing of this commentary. I am particularly indebted to Jin-Long Chen for extensive help with background material, Michele Cleary and Sarah Graff for editorial help, and Barbara Graves, Lawrence McIntosh, Dimitar Nikolov, Stephen Burley, Thomas Li, and Cynthia Wolberger for their generous provision of figures. Finally, I express my sincerest regrets to the many scientists whose work was presented at the meeting but not discussed in this commentary because of space limitations.

\section{References}

Allison, L.A, M. Moyle, M. Shales, and C.J. Ingles. 1985. Extensive homology among the largest subunits of eukaryotic and prokaryotic RNA polymerases. Cell 42: 599-610.

Allison, L.A., I.K. Wong, V.D. Fitzpatrick, M. Moyle, and C.J. Ingles. 1988. The C-terminal domain of the largest subunit of RNA polymerase II of Saccharomyces cerevisiae, Drosophila melanogaster, and mammals: A conserved structure with an essential function. Mol. Cell Biol. 8: 321-329.

Bagby, S., S. Kim, E. Maldonado, K.I. Tong, D. Reinberg, and M. Ikura. 1995. Solution structure of the C-terminal core domain of human TFIlB: Similarity to cyclin $A$ and interaction with TATA-binding protcin. Cell 82: 857-867.

Barberis, A., J. Pearlberg, N. Simkovich, S. Farrell, P. Reinagel, C. Bamdad, G. Sigal, and M. Ptashne. 1995. Contact with a component of the polymerase II holoenzyme suffices for gene activation. Cell 81: $359-368$.

Bartolomei, M.S., N.F. Halden, C.R. Cullen, and J.L. Corden. 1988. Genetic analysis of the repetitive carboxyl-terminal domain of the largest subunit of mouse RNA polymerase II. Mol. Cell. Biol. 8: 330-339.

Bienz, M. and J. Müller. 1995. Transcriptional silencing of homeotic genes in Drosophila. BioEssays 17: 775-784.

Briggs, M.R., C. Yokoyama, X. Wang, M.S. Brown, and J.L. Goldstein. 1993. Nuclear protein that binds stcrol regulatory element of low density lipoprotein receptor promoter. /. Biol. Chem. 268: 14490-14496.

Breathnach, R. and P. Chambon. 1981. Organization and expression of eucaryotic split genes coding for proteins. Annu. Rev. Biochem. 50: 349-383.

Brent, R. and M. Ptashne. 1985. A eukaryotic transcriptional activator beaxing the DNA specificity of a prokaryotic repressor. Cell 43: 729-736.

Buratowski, S., S. Hahn, L. Guarente, and P.A. Sharp. 1989. Five intermediate complexes in transcription initiation by RNA polymerase II. Cell 56: 549-561.

Cairns, B.R., Y.-I. Kim, M.H. Sayre, B.C. Laurent, and R.D. Kornberg. 1994. A multisubunit complex containing the 
SWI1/ADR6, SW12/SNF2, SWI3, SNF5, and SNF6 gene products isolated from yeast. Proc. Natl. Acad. Sci. 91: 1950-1954.

Chen, J.D. and R.M. Evans. A transcription corepressor that interacts with nuclear hormone receptors. Nature 377: 454 457.

Chen, J.-L., L. D. Attardi, C.P. Verrijzer, K. Yokomori, and R. Tjian. 1994. Assembly of recombinant TFIID reveals differential coactivator requirements for distinct transcriptional activators. Science 79: 93-105.

Chiang, C.-M., H. Ge, Z. Wang, A. Hoffman, and R.G. Roeder. 1993. Unique TATA binding protein-containing complexes and cofactors involved in transcription by RNA polymerases II and III. EMBO I. 12: 2749-2762.

Cisek, L.J. and J.L. Corden. 1989. Phosphorylation of RNA polymerase by the murine homologue of the cell-cycle control protein cdc2. Nature 339: 679-684

Comai, L., N. Tanese, and R. Tjian. 1992, The TATA-binding protein and associated factors are integral components of the RNA polymerase I transcription factor, SLi. Cell 68: 965976.

Corden, J., D.L. Cadena, J.M. Ahearn, and M.E. Dahmus. 1985. A unique structure at the carboxyl terminus of the largest subunit of eukaryotic RNA polymerase II. Proc. Natl. Acad. Sci. 82: 7934-7938.

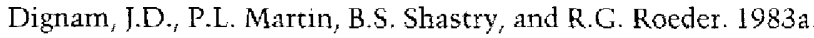
Eukaryotic gene transcription with purificd components. Methods Enzymol. 101: 582-598.

Dignam, J.D., R.M. Lebovitz, and R.G. Roeder. 1983b. Accurate transcription initiation by RNA polymerase II in a soluble extract from isolated mammalian nuclei. Nucleic Acids Res. 11: $1475-1489$.

Dillin, A. and I. Rine. 1995. On the origin of a silencer. Trends Biochem. Sci. 20: 231-235.

Dynlacht, B.D., T. Hoey, and R. Tijian. 1991. Isolation of coactivators associated with the TATA-binding protein that mediate transcriptional activation. Cell 66: 563-576.

Donaldson, L.W., I.M. Peterson, B.J. Graves, and L.P. McIntosh. 1996. Solution structure of the ETS domain from murine Ets-1: A winged helix-turn-helix motif. EMBO /. 15: 125134.

Eberhard, D., L. Tora, J.-M. Egly, and I Grummt. 1993. A TPBcontaining multiprotein complex (TIF-IB) mediates transcription specificity of murinc RNA polymerase I. Nucleic Acids Res. 21: $4180 \cdot 4186$

Feaver, W.J., J.Q. Svejstrup, N.L. Henry, and R.D. Kornberg. 1994. Relationship of CDK-activating kinase and RNA polymerase II CTD kinase TFIIH/TFIIK. Cell 79: 1103-1109.

Flanagan, P.M., R.J. Kelleher, M.H. Sayer, H. Tschochner, and R.D. Kornberg. 1991. A mediator required for activation of RNA polymerase II transcription in vitro. Nature 350: 436438.

Giardina, C., M. Perez-Riba, and J.T. Lis. 1992. Promoter melting and TFIID complexes on Drosophila genes in vivo. Genes \& Dev. 6: $2190-2200$.

Goodrich, J.A. and R. Tiian. 1994. TBP-TAF complexes: Selectivity factors from eukaryotic transcription. Curr. Opin. Cell Biol. 6: 403-409.

Hahn, S., S. Buratowski, P.A. Sharp, and L. Guarente. 1989. Isolation of the gene encoding the yeast TATA binding protein TFIID: A gene identical to the SPT15 suppressor of Ty element insertions. Cell 58: 1173-1181.

Hengartner, C.J., C.M. Thompson, J. Zhang, D.M. Chao, S.-M. Liao, A.J. Koleske, S. Okamura, and R.A. Young. 1995. Association of an activator with an RNA polymerase II holoenzyme. Genes \& Dev. 9: 897-910.
Hernandez, N. 1993. TBP, a universal eukaryotic transcription factor? Genes \& Dev. 7: 1291-1308.

Himmelfarb, H.J., J. Pearlberg, D. Last, and M. Ptashne. 1990. Gall1P: A yeast mutation that potentiates the effect of weak GAL4-derived activators. Cell 63: 1299-1309.

Horlein, A.J., A.M. Naar, T. Heinzel, J. Torchia, B. Gloss, R. Kurokawa, A. Ryan, Y. Kamei, M. Soderstrom, C.K. Glass, and M.G. Rosenfeld. 1995. Ligand-independent repression by the thyroid hormone receptor mediated by a nuclear receptor co-repressor. Natire 377: 397-404.

Hua, X., C. Yokoyama, J. Wu, M.R. Briggs, M.S. Brown, I.L. Goldstein, and X. Wang. 1993. SREBP-2, a second basic-helix-loop-helix-leucine zipper protein that stimulates transcription by binding to a sterol regulatory element. Proc. Natl. Acad. Sci. 90: 11603-11607.

Johnson, A.D. 1995. Molecular mechanisms of cell-type determination in budding yeast. Curr. Opin. Genet. Dev. 5: 552558.

Keegan, L., G. Gill, and M. Ptashne. 1986. Separation of DNA binding from the transcription-activation function of a eukaryotic transcriptional activator protein. Science 231: 669704.

Kelleher, R.J., P.M. Flanagan, and R.D. Kornberg. 1990. A novel mediator between activator proteins and the RNA polymerase II transcription apparatus. Cell 61: 1209-1215.

Kim, J.L., D.B. Nikolov, and S.K. Burley. 1993a. Co-crystal structure of TBP recognizing the minor groove of a TATA element. Nature 365: 520-527.

Kim, Y., J.H. Geiger, S. Hahn, and P.B. Sigler. 1993b. Crystal structure of a yeast TBP/TATA-box complex. Nature 365: $512-520$.

Kim, Y.-J., S. Björklund, Y. Li, M.H. Sayre, and R.D. Kornberg. 1994. A multiprotein mediator of transcriptional activation and its interaction with the C-terminal repeat domain of RNA polymerase II. Cell 77: 599-608.

Koleske, A.J. and R.A. Young. 1994. An RNA polymerase II holoenzyme responsive to activators. Nature 368: 466-469.

Koleske, A.J., S. Buratowski, M. Nonet, and R.A. Young. 1992. A novel transcription factor reveals a functional link between the RNA polymerase II CTD and TFIID. Cell 69: 883894

Kuchin, S., P. Yeghiayan, and M. Carlson. 1995. Cyclin-dependent protein kinase and cyclin homologs SSN3 and SSN8 contribute to transcriptional control in yeast. Proc. Natl. Acad Sci. 92: 4006-4010.

LaMarco, K. 1994. Dissecting a complex process. Proc. Natl. Acad. Sci. 91: 2886-2887.

Laurent, B.C., T. Treich, and M. Carlson. 1993. The yeast SNF2/ SWI2 protein has DNA-stimulated ATPase activity required for transcriptional activation. Genes \& Dev, 7:583-591,

Layboum, P.J. and M.E. Dahmus. 1989. Transcription-dependent structural changes in the C-terminal domain of mammalian RNA polymerase subunit IIa/o. /. Biol. Chem. 264: 6693-6698.

- 1990. Phosphorylation of RNA polymerase Ila occurs subsequent to interaction with the promoter and before the initiation of transcription. J. Biol. Chem. 265: 13165-13173.

Lee, J.M. and A.L. Greenleaf. 1989. A protein kinase that phosphorylates the C-terminal repeat domain of the largest subunit of RNA polymerase II. Proc. Natl. Acad. Sci. 86: 36243628.

Lee, S. and S. Hahn. 1995. Model for binding of transcription factor TFIIB to the TBP-DNA complex. Nature 376: 609612 .

Li, T., M.R. Stark, A.D. Johnson, and C. Wolberger. 1995. Crystal structure of the MATal/MAT $\alpha 2$ homeodomain hetcro- 
dimer bound to DNA. Science 270: 262-269.

Liao, S.M., I. Zhang, D.A. Jeffery, A.J. Koleske, C.M. Thompson, D.M. Chao, M. Vilioen, H.J. van Vuuren, and R.A. Young. 1995. A kinase-cyclin pair in the RNA polymerase II holoenzyme. Nature 374: 193-196.

Lis, J. and C. Wu. 1993. Protein traffic on the heat shock promoter: Parking, stalling, and trucking along. Cell 74: 1-4.

Lobo, S.M., M. Tanaka, M.L. Sullivan, and N. Hernandez. 1992. A TBP complex essential for transcription from TATA-less but not TATA-containing RNA polymerase III promoters is part of the TFIIIB fraction. Cell 71: 1029-1040.

Luse, D.S. and R.G. Roeder. 1980. Accurate transcription initiation on a purified mouse $\beta$-globin DNA fragment in a cellfree system. Cell 20: 691-699.

Ma, I. and M. Ptashne. 1987. Deletion analysis of GAL4 defines two transcriptional activating segments. Cell 48: 847-853.

Manley, J.L., A. Fire, A. Cano, P.A. Sharp, and M.L. Gefter. 1980. DNA-dependent transcription of adenovirus genes in a soluble whole-cell extract. Proc. Natl. Acad. Sci. 77: 38553859 .

McKnight, S.L and K.R. Yamamoto (eds). 1992. Transcriptional regulation. Cold Spring Harbor Laboratory Press, Cold Spring Harbor, NY.

Morgan, D.O. 1995. Principles of CDK regulation. Nature 374: $131-134$

Nasmyth, K. 1993. Control of the yeast cell cycle by $\mathrm{Cdc} 28$ kinasc. Curr. Opin. Cell Biol. 5: 166-179.

Nikolov, D.B., H. Chen, E.D. Halay, A.A. Usheva, K. Hisatake, D.K. Lee, R.G. Roeder, and S.K. Burley. 1995. Crystal structure of a TFIIB-TBP-TATA-element ternary complex. Nature 377: $119-128$

Nonet, M.L. and R.A. Young. 1987. Intragenic and extragenic suppressors of mutations in the heptapeptide repeat domain of Saccharomyces cerevisiae RNA polymerase II. Genetics 123: 715-724

O'Brien, T., S. Hardin, A. Greenleaf, and J.T. Lis. 1994. Phosphorylation of RNA polymerase II C-terminal domain and transcriptional elongation. Nature 370: 75-77.

Ossipow, V., J.-P. Tassan, E.A. Nigg, and U. Schibler. 1995. A mammalian RNA polymerase II holoenzyme containing all components required for promoter-specific transcription initiation. Cell 83: 137-146.

Pellegrini, L., S. Tan, and T.J. Richmond. 1995. Structure of serum response factor core bound to DNA. Nature 376: 490498.

Petersen, J.M., J.J. Skalicky, L.W. Donaldson, L.P. McIntosh, T. Alber, and B. Graves. 1995. Modulation of transcription fac tor Ets-1 DNA binding: DNA-induced unfolding of an $\alpha$ helix. Science 269: 1866-1869.

Peterson, C.L., A. Dingwail, and M.P. Scott. 1994. Five SWI/ SNF gene products are components of a large multisubunit complex required for transcriptional enhancement. Proc. Natl. Acad. Sci. 91: 2905-2908.

Poon, D. and P.A. Weil. 1993. Immunopurification of yeast TATA-binding protein and associated factors. $/$. Biol. Chem. 268: $15325-15328$.

Poon, D., Y. Bai, A.M. Campbell, S. Bjorklund, Y.J. Kim, S. Zhou, R.D. Kornberg, and P.A. Weil. 1995. Identification and charactcrization of a TFIID-like multiprotein complex from Saccharomyces cerevisiae. Proc. Natl. Acad. Sci. 92: 8224 8228.

Ptashne, M. 1992. A genetic switch. Cell Press, Cambridge, MA.

Reese, J.C., L. Apone, S.S. Walker, L.A. Griffin, and M.R. Green. 1994. Yeast $\mathrm{TAF}_{\mathrm{II}} \mathrm{S}$ in a multisubunit complex required for activated transcription. Nature 371: 523-527.

Rougvie, A.E. and J.T. Lis. 1988. The RNA polymerase II mol- ecule at the $5^{\prime}$ end of the uninduced $h s p 70$ gene of $D$. mel anogaster is transcriptionally engaged. Cell 54: 795-804.

Roy, R., I.P. Adamczewski, T. Seroz, W. Vermeulen, I.-P. TasSan, L. Schaeffer, E.A. Nigg. J.H.J. Hoeijmakers, and J.-M. Egly. 1994. The MOl5 cell cycle kinase is associated with the TFIIH transcription-DNA repair factor. Cell 79: 10931101.

Sadowski, C.L., R.W. Henry, S.M. Loho, and N. Hernandez. 1993. Targeting TBP to a non-TATA box cis-regulatory element: A TBP-containing complex activates transcription from snRNA promoters through the PSE. Genes \& Dev. 7: 1535-1548.

Sakai, D.D., S. Helms, J. Carlstedt-Duke, J.A. Gustafsson, F.M. Rottman, and K.R. Yamamoto. 1988. Hormone-mediated repression: A negative glucocorticoid response element from the bovine prolactin gene. Genes \& Dev. 2: 1144-1154.

Serizawa, H., T.P. Mäkelä, J.W. Conaway, R.C. Conaway, R.A. Weinberg, and R.A. Young. 1992. Nature 374: 280-282.

Shiekhattar, R., F. Mermelstein, R.P. Fisher, R. Drapkin, B. Dynlacht, H.C. Wessling, D.O. Morgan, and D. Reinberg. 1995. CDK-activating kinase complex is a component of human transcription factor TFIIH. Nature 374: 283-287.

Smale, S.T. and D. Baltimore. 1989. The "initiator" as a transcription control element. Cell 57: 103-113.

Smith, J.R., T.F. Osborne, J.L. Goldstein, and M.S. Brown. 1990. Identification of nucleotides responsible for enhancer activity of sterol regulatory element in low density lipoprotein receptor gene. 7. Biol. Chem. 265: 2306-2310.

Svaren, J., J. Schmitz, and W. Horz. 1994. The transactivation domain of Pho4 is required for nucleosome disruption at the PHO5 promoter. EMBO I. 13: 4856-4862.

Taggart, A.K.P., T.S. Fisher, and B.F. Pugh. 1992. The TATAbinding protein and associated factors are components of Pol IIl transcription factor TFIIIB. Cell 71: 1015-1028.

Tamkun, J.W., R. Deuring, M.P. Scott, M. Kissinger, A.M. Pattatucci, T.C. Kaufman, and J.A. Kennison. 1992. brahma: A regulator of Drosophila homeotic genes structurally related to the yeast transcriptional activator SNF2/SW12. Cell 68: $561-572$.

Tanese, N., F. Pugh, and R. Tjian. 1991. Coactivators for a proline-rich activator purified from the multisubunit human TFIID complex. Genes \& Dev. 5: 2212-2224.

Thompson, C.M., A.J. Koleske, D.M. Chao, and R.A. Young. 1993. A multisubunit complex associated with the RNA polymcrase II CTD and TATA-binding protein in yeast. Cell 73: $1361-1375$.

Timmers, H.T.M. and P.A. Sharp. 1991. The mammalian TFIID protein is present in two functionally distinct complexes. Genes \& Dev. 5: 1946-1956.

Treich, I., B.R. Cairns, T. de los Santos, E. Brewster, and M. Carlson. 1995. SNF11, a new component of the yeast SNFSWI complex that interacts with a conserved region of SNF2. Mol. Cell. Biol. 15: 4240-4248.

Triesman, R. 1994. Ternary complex factors: Growth factorregulated transcriptional activators. Curr. Opin. Genet. Dev. 4: 96-101

Tsukiyama, T., P.B. Becker, and C. Wu. 1994. ATP-dependent nucleosome disruption at a heat-shock promoter mediated by binding of GAGA transcription factor. Nature 367: 525532

Van Dyke, M.W., R.G. Roeder, and M. Sawadogo. 1988. Physical analysis of transcription preinitiation complex assembly on a class II gene promoter. Science 241: 1335-1338.

Van Dyke, M.W., M. Sawadogo, and R.G. Roeder. 1989. Stability of transcription complexes on class II genes. Mol. Cell. Biol. 9: $342-344$ 
Wang, X., M.R. Briggs, X. Hua, C. Yokoyama, J.L. Goldstein, and M.S. Brown. 1993. Nuclear protein that binds sterol regulatory element of low density lipoprotein receptor promoter. I. Biol. Chem. 268: 14497-14504.

Wang, X., R. Sato, M.S. Brown, X. Hua, and J.L. Goldstein. 1994. SREBP-1, a membrane-bound transcription factor released by sterol-regulated protcolysis. Cell 77: 53-62.

Weeks, J.R., S.E. Hardin, J. Shen, J.M. Lee, and A.L. Greenleaf. 1993. Locus-specific variation in phosphorylation state of RNA polymerase II in vivo: Corrclations with gene activity and transcript processing. Genes \& Dev. 7: 2329-2344.

Weil, P.A., D.S Luse, J. Segall, and R.G. Roeder. 1979. Selective and accurate initiation of transcription at the $\mathrm{AD} 2$ major latc promoter in a soluble system dependent on purified RNA polymerase II and DNA. Cell 18: 469-484.

White, R.J. and S.P. Jackson. 1992. Mechanism of a TATA-binding protein recruitment to a TATA-less class III promoter. Cell 71: 1041-1053.

Winston, F. and M. Carlson. 1992. Yeast SNF/SWI transcriptional activators and the SPT/SIN chromatin connection. Trends Genet. 8: 387-391.

Yankulov, K., J. Blau, T. Purton, S. Roberts, and D.L. Bentley. 1994. Transcriptional elongation by RNA polymerase II is stimulated by transactivators. Cell 77: 749-759.

Yokoyama, C., X. Wang, M.R. Briggs, A. Admon, J. Wu, X. Hua, J.L. Goldstein, and M.S. Brown. 1993. SREBP-1, a basic-helixloop-helix-leucine zipper protein that controls transcription of the low density lipoprotein receptor gene. Cell 75: 187197.

Zawel, L., K.P. Kumar, and D. Reinberg. 1995. Recycling of the general transcription factors during RNA polymerase II transcription. Genes \& Dev. 9: 1479-1490.

Zehring, W.A., J.M. Lee, J.R. Weeks, R.S. Jokerst, and A.L. Greenleaf. 1988. The C-terminal repeat domain of RNA polymerase II largest subunit is essential in vivo but is not required for accurate transcription initiation in vitro. Proc. Natl. Acad. Sci. 85: 3698-3702.

Zhou, Q., P.M. Lieberman, T.G. Boyer, and A.J. Berk. 1992. Holo-TFIID supports transcriptional stimulation by diverse activators and from a TATA-less promoter. Genes \& Dev. 6: $1964-1974$. 


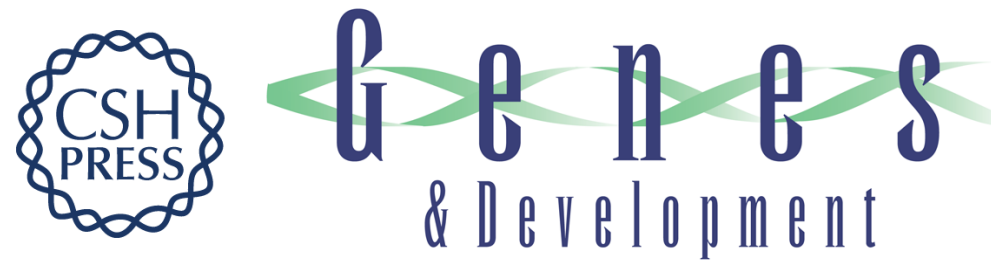

\section{Transcription revisited: a commentary on the 1995 Cold Spring Harbor Laboratory meeting, "Mechanisms of Eukaryotic Transcription".}

S L McKnight

Genes Dev. 1996, 10:

Access the most recent version at doi:10.1101/gad.10.4.367

References This article cites 96 articles, 35 of which can be accessed free at: http://genesdev.cshlp.org/content/10/4/367.full.html\#ref-list-1

License

Email Alerting Service

Receive free email alerts when new articles cite this article - sign up in the box at the top right corner of the article or click here.

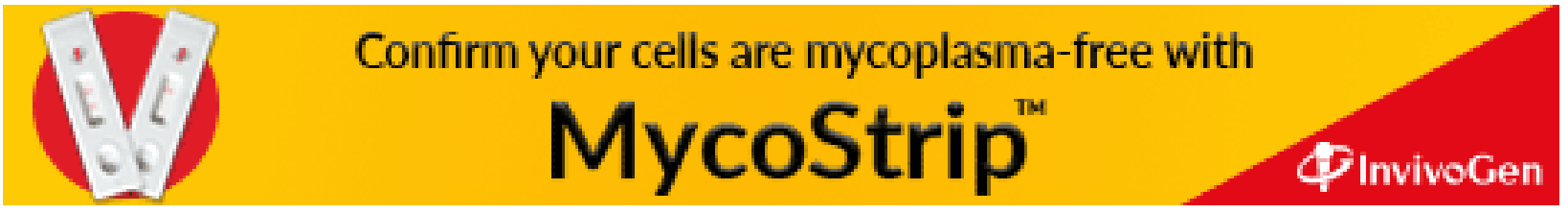

